N. Hiraishi ${ }^{1,4}$, N. Nishiyama ${ }^{2}$, K. Ikemura ${ }^{3}$, J.Y.Y. Yau ${ }^{4}$, N.M. King ${ }^{1}$, J. Tagami ${ }^{5}$, D.H. Pashley ${ }^{6}$, and F.R. Tay ${ }^{1 *}$

${ }^{1}$ Paediatric Dentistry and Orthodontics, Faculty of Dentistry, The University of Hong Kong, Prince Philip Dental Hospital, 34 Hospital Road, Hong Kong SAR, China; ${ }^{2}$ Department of Dental Materials, Nihon University School of Dentistry at Matsudo, Chiba, Japan; ${ }^{3}$ Department of Research and Development, Shofu Inc., Kyoto, Japan; ${ }^{4}$ Oral Biosciences, Faculty of Dentistry, The University of Hong Kong, Hong Kong SAR, China; ${ }^{5}$ Department of Operative Dentistry, Tokyo Medical and Dental University, Tokyo, Japan; and ${ }^{6}$ Department of Oral Biology and Maxillofacial Pathology, School of Dentistry, Medical College of Georgia, Augusta, GA, USA; *corresponding author,kfctay@netvigator.com

J Dent Res 84(7):653-658, 2005

\begin{abstract}
Water is required to ionize acid resin monomers for demineralization of tooth substrates. We tested the null hypothesis that altering the water concentration in two-step self-etching primers has no effect on their aggressiveness and bonding efficacy to dentin. Five experimental self-etching primers were prepared with resin-water-ethanol volume ratios of 9-0-1, 8-1-1, 7-2-1, 5-4-1, and 36-1. They were applied to smear-layer-covered dentin, followed by a bonding resin and composite build-ups for microtensile bond testing and TEM examination of tracer penetration. Increasing water concentration from $0-60 \mathrm{vol} \%$ improved acidic monomer ionization that was manifested as increasing hybrid layer thickness. However, significantly higher bond strength was observed in the 7-2-1 group, with minimal nanoleakage in the corresponding hybrid layer. When self-etching primers are formulated, a balance must be achieved to provide sufficient water for adequate ionization of the acidic monomers, without lowering the resin concentration too much, to optimize their bonding efficacy to dentin.
\end{abstract}

KEY WORDS: acidic monomer, water content, dentin, microtensile bond strength, nanoleakage.

Received June 2, 2004; Last revision February 27, 2005; Accepted April 8, 2005

\section{Water Concentration in Self-etching Primers Affects their Aggressiveness and Bonding Efficacy to Dentin}

\section{INTRODUCTION}

T

he creation of stable resin-dentin bonds relies on the formation of hybrid

layers that consist of completely or partially demineralized dentin and well-infiltrated, well-polymerized resins (Van Meerbeek et al., 2003). Unlike total-etch adhesives, self-etch adhesives are non-rinsed and should not exhibit discrepancies between the depths of demineralization and resin infiltration (Nakabayashi and Saimi, 1996), since the functions of etching and priming are simultaneously performed by the acidic monomers (Chigira et al., 1994; Watanabe et al., 1994). However, water may not be completely removed from these adhesives, due to the entrapment of free water in adhesive solvent (Pashley et al., 1998) or dentinal tubules (Chersoni et al., 2004), and the retention of bound water via hydrogen bonding with the acidic and hydrophilic monomers (Klotz et al., 1996; Tay et al., 2003). These water-filled voids may be visualized as different patterns of nanoleakage with the use of silver nitrate tracers (Tay et al., 2002; Li et al., 2003; Hashimoto et al., 2004).

Bonding to tooth structure via the self-etching approach is achieved by increasing the concentrations of acidic methacrylate monomers (Hayakawa et al., 1998). These monomers contain one or more acidic functional groups and have comparatively low, first-acid dissociation constants (pKa1). Water is required to dissociate these weak acids into ionized forms for permeation of the smear layer and demineralization of the underlying intact tooth substrates (Tay and Pashley, 2001; PradellePlasse et al., 2004). A hydrophilic monomer, 2-hydroxyethyl methacrylate (HEMA), is often included as a transitional polymerizable solvent, since many of the acidic monomers are only mildly water-soluble (Chigira et al., 1989). Although the aggressiveness of self-etch adhesives is largely determined by the concentrations and the $\mathrm{pKa}$ values of these acidic monomers (Nishiyama et al., 2004b), differences in water concentration may also contribute to partial or total dissociation of the acid functionalities, creating a variable extent of fractional ionization of these monomers (Anseth et al., 1996).

The effect of water concentration on the aggressiveness and bonding efficacy of self-etching primers to dentin has not been thoroughly investigated, since commercially available systems differ in their resin monomer compositions, adhesive solvents, and water contents. Thus, it is difficult to study the contribution of a single factor without resorting to a modeling approach. In this study, we created experimental self-etching primers using one acidic resin monomer, one hydrophilic resin monomer, a fixed amount of ethanol, and variable amounts of water for simultaneous etching and priming of dentin. The null hypothesis tested was that altering the water concentration in two-step self-etching primers has no effect on their aggressiveness and bonding efficacy to dentin. 

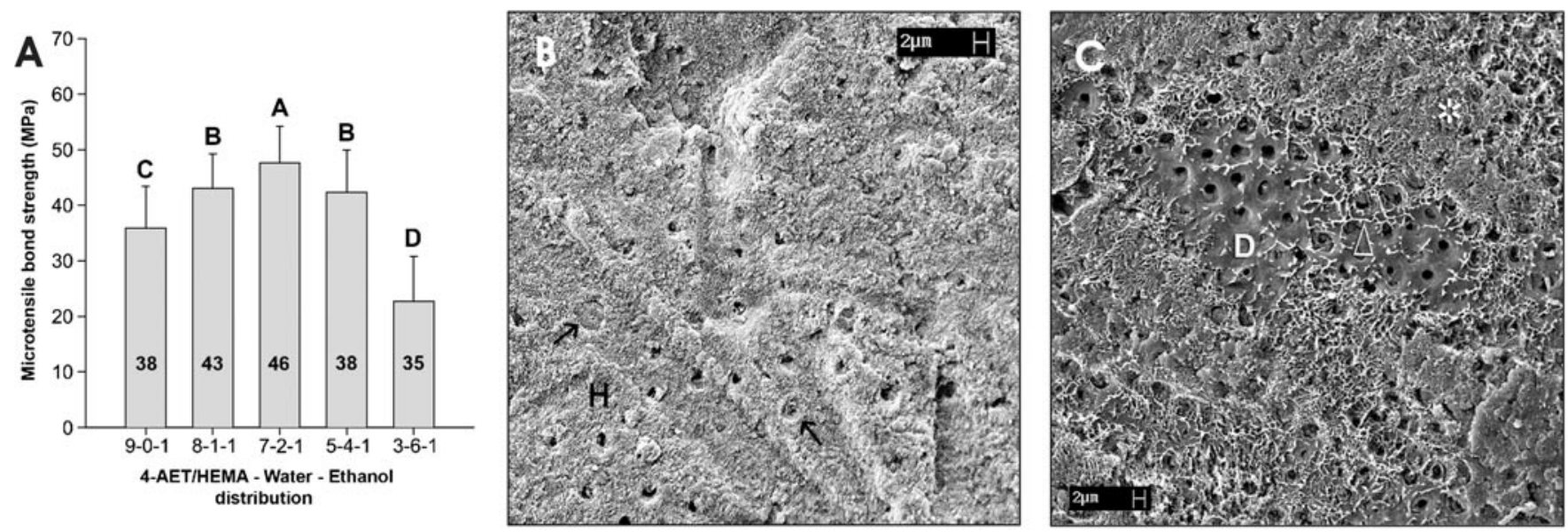

Figure 1. Microtensile bond strengths and representive SEM micrographs from the 5 experimental groups. (A) Microtensile bond strengths of the 5 two-step, experimental 4-AET/HEMA self-etching primer solutions: Group 9-0-1 (35.9 $\pm 7.5 \mathrm{MPa})$, Group 8-1-1 (43.1 \pm 6.1 MPa), Group 7-2-1 $(47.6 \pm 6.6 \mathrm{MPa})$, Group 5-4-1 $(42.3 \pm 7.6 \mathrm{MPa})$, and Group 3-6-1 $(22.6 \pm 8.1 \mathrm{MPa})$. The number inside each bar represents the number of specimens tested for that group. There were no premature failures in any of the groups. Groups with the same upper-case letters are not statistically significant $(P>0.05)$. (B) SEM micrograph of an adhesive failure from the group with the highest mean bond strength (Group 7-2-1), showing the surface of the fractured hybrid layer that appeared comparatively solid. Hybridized smear plugs (arrows) can be seen within some dentinal tubules. (C) SEM micrograph of an adhesive failure from the group with the lowest mean bond strength (Group 3-6-1). The surface of the hybrid layer was porous (asterisk), and some incompletely infiltrated collagen fibrils (open arrowhead) can be identified along the fractured interface. The condition of the hybrid layer reflects the extensive nanoleakage observed in the TEM (Fig. 4D). D: non-hybridized dentin.

\section{MATERIALS \& METHODS}

Twenty-five non-carious human third molars were collected after the patients' informed consent was obtained under a protocol reviewed and approved by the Human Assurance Committee of the Medical Collage of Georgia. The molars were stored in $0.5 \%$ chloramine $\mathrm{T}$ at $4^{\circ} \mathrm{C}$, and were used within 1 mo following extraction. Flat dentin surfaces were created perpendicular to the tooth's longitudinal axis by means of a slow-speed diamond saw (Isomet, Buehler Ltd., Lake Bluff, IL, USA), for the removal of occlusal enamel and superficial dentin. Each surface was ground with 180-grit silicon carbide paper under running water for $30 \mathrm{sec}$ just before bonding occurred.

\section{Preparation of Experimental Self-etching Primers}

An anhydrous stock primer solution was first prepared by dissolving 4-acryloxyethyltrimellitic acid (4-AET) powder in HEMA. 4-AET was synthesized according to the method described by Ikemura and Endo (1998). The stock solution consisted of 40 wt\% 4-AET, 59 wt\% HEMA, and 1 wt\% 2,4,6-trimethylbenzoyldiphenyl phosphine oxide (Aldrich Chemical Company, Milwaukee, WI, USA) as the photoinitiator. The latter was used in lieu of camphorquinone because of its greater activity for photopolymerization of the acidic HEMA solution (Ikemura, unpublished results).

Five experimental two-bottle-type, self-etching primers were subsequently prepared, with the stock solution as component A, and absolute ethanol/water as component B. The resin-ethanolwater volume ratios after the 2 components were mixed were: 9-01 (water-free), 8-1-1 (10 vol\% water); 7-2-1 (20 vol\%), 5-4-1 (40 vol\%), and 3-6-1 (60 vol\%). Their $\mathrm{pH}$ values at ambient temperature $\left(20-25^{\circ} \mathrm{C}\right)$, as determined with a digital $\mathrm{pH}$ meter (Model 501, Orion Research, Inc., Beverly, MA, USA), were 1.97 \pm 0.06 (Group 8-1-1), $1.93 \pm 0.06$ (Group 7-2-1), $1.90 \pm 0.04$ (Group 5-4-1), and $1.86 \pm 0.12$ (Group 3-6-1). Group 9-0-1 could not be measured with the $\mathrm{pH}$ meter, since we could not completely dehydrate the electrolyte, and the $\mathrm{pH}$ value of $7.00 \pm 0.00$ was measured with litmus paper. The experimental self-etching primers were used immediately after the 2 components were mixed, to avoid hydrolysis of the acidic and hydrophilic monomers in the presence of water (Nishiyama et al., 2004a).

\section{Tensile Bond Strength and Fractographic Evaluation}

Three teeth were used for each of the 5 experimental groups. Immediately after the 2 components were mixed, each self-etching primer was applied with agitation on the dentin surface for $20 \mathrm{sec}$. Without being rinsed, the solution was gently air-dried for evaporation of the solvent. The primed dentin was bonded with Fluoro-Bond bonding agent (Shofu Inc., Kyoto, Japan) and lightcured for $20 \mathrm{sec}$ via a halogen light-curing unit operated at 600 $\mathrm{mW} / \mathrm{cm}^{2}$. Composite build-ups were constructed with a light-cured resin composite (Beautifil, Shofu Inc.) in 5 one-mm-thick increments.

After being stored in distilled water at $37^{\circ} \mathrm{C}$ for $24 \mathrm{hrs}$, the bonded teeth were sectioned occluso-gingivally into $0.9 \times 0.9-\mathrm{mm}$ composite-dentin beams, according to the 'non-trimming' technique of the microtensile test. Between 35 and 46 beams were available for bond testing in each group. Specimens were stressed to failure under tension by means of a universal testing machine (Model 4440; Instron, Inc., Canton, MA, USA) at a crosshead speed of 1 $\mathrm{mm} / \mathrm{min}$. Bond strength data were statistically analyzed by oneway ANOVA and Tukey's multiple-comparison tests, with statistical significance set at $\alpha=0.05$.

The failure modes of all specimens were initially examined with a stereomicroscope (Nikon SMZ10, Tokyo, Japan) at 30X magnification and were classified as adhesive, cohesive in dentin/composite, or mixed failures. For each experimental group, each type of failure mode was expressed as a percentage of the total number of specimens in that group. Four representative fractured beams from each group with tensile bond strengths that were close to the mean bond strength of that group were examined with scanning electron microscopy (SEM). In addition, 4 specimens 
from each group with tensile bond strengths that were either higher or lower than the corresponding mean bond strength of that group were also examined. The dentin sides of the fractured beams were air-dried, sputter-coated with gold/palladium, and examined by SEM (Cambridge Stereoscan 440, Cambridge, United Kingdom) at $10 \mathrm{kV}$.

\section{Transmission Electron Microscopy (TEM)}

Two teeth from each group were similarly treated with the self-etching primer solution and further bonded with Fluoro-Bond bonding agent. The bonded teeth were coupled to a microfilled resin composite (EPICTMPT, Parkell Inc., Farmingdale, NY, USA) to facilitate ultramicrotomy. The teeth were sectioned into $0.9-\mathrm{mm}$ serial slabs. The 2 widest slabs from each tooth were used for TEM examination. For evaluation of the aggressiveness of various self-etching primers, 1 slab from each tooth was completely demineralized in ethylene diamine tetraacetic acid. After laboratory processing according to the protocol reported by Tay et al. (1999), 90-nm-thick epoxy-resin-embedded sections were prepared and stained with uranyl acetate and lead citrate.

For examining the extent of resin infiltration with resin-dentin interfaces formed by the self-etching primers, we immersed the second slab from each tooth in a $50 \mathrm{wt} \%$ ammoniacal silver nitrate solution for $24 \mathrm{hrs}$, according to the silver-impregnation protocol reported by Tay et al. (2002). After reduction of the diamine silver ions, the silver-impregnated slabs were processed for TEM examination without further demineralization and examined unstained. Both types of sections were examined by TEM (CM100, Philips, Eindhoven, The Netherlands) at $80 \mathrm{kV}$.

\section{RESULTS}

Significant differences were observed for the tensile bond strengths of the 5 experimental self-etching primers (Fig. 1A). Group 7-2-1 specimens exhibited the highest strength (47.6 \pm 6.6 MPa) $(\mathrm{P}<0.05)$. This was followed by Groups 8-1-1 (43.1 \pm $6.1 \mathrm{MPa})$ and 5-4-1 (42.3 $\pm 7.6 \mathrm{MPa})$, which were not significantly different from each other, but were significantly higher than Group 9-0-1 (35.9 \pm 7.5 MPa). Group 3-6-1 exhibited the lowest bond strength $(22.6 \pm 8.1 \mathrm{MPa})$. Between 8 and $15 \%$ mixed and cohesive failures were observed in all groups, with the exception of Group 3-6-1, in which bond

failures were exclusively adhesive.

Morphologic differences among the adhesive failures were seen between the higher-bond-strength groups and those with lower bond strengths. In Group 7-2-1 (higher bond strengths), for example, the fractured surface of the hybrid layer remained comparatively solid (Fig. 1B). Conversely, the fractured hybrid layer surface was porous in Group 3-6-1 (lower bond strengths), from which denuded collagen fibrils were detached from the resinous components (Fig. 1C). Specimens with bond strengths higher or lower than those of the corresponding mean bond strength of a particular group depicted either mixed failures or cohesive failures within the weaker dentin (not shown).

Increasing the water concentration from $0-60 \mathrm{vol} \%$ resulted in improved acidic monomer ionization, manifested as an 

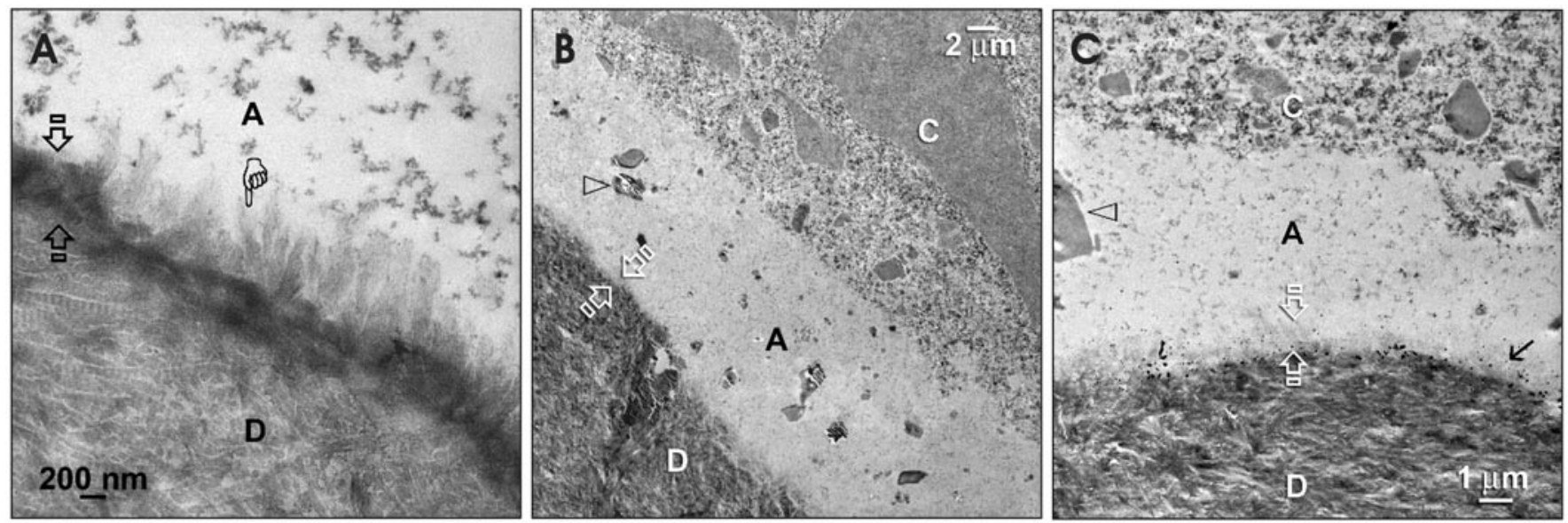

Figure 3. TEM micrographs from the experimental group with the highest bond strength (Group 7-2-1; 20 vol\% water). C, composite; A, filled adhesive; D, dentin; open arrowhead, fully pre-reacted glass-ionomer-type fillers (F-PRG) from the Fluoro-Bond bonding resin. (A) Stained, demineralized section showing a 500-nm- to 1- $\mu \mathrm{m}$-thick hybrid layer (between open arrows). The smear layer was completely dissolved, and collagen fibrils (pointer) from the intact dentin exhibit a 'shag carpet' appearance. (B) The corresponding unstained, undemineralized section after tracer penetration, showing the overall absence of nanoleakage from the resin-dentin interface. The partially demineralized zone (between open arrows) corresponded to the hybrid layer depicted in the stained section. (C) A high-magnification view of Fig. 3B, showing the presence of minimal nanoleakage that existed in the form of isolated silver grains (arrow) within the partially demineralized zone (between open arrows).

increase in the depth of the hybrid layers created by the selfetching primers. Hybrid layer thickness varied from $0.2 \mu \mathrm{m}$ in Groups 9-0-1 (Fig. 2A) and 8-1-1 (Fig. 2C), to 0.5-1 $\mu \mathrm{m}$ in Group 7-2-1 (Fig. 3A), to 1.5-2 $\mu \mathrm{m}$ in Groups 5-4-1 (Fig. 4A) and 3-6-1 (Fig. 4C).

Extensive nanoleakage was observed within the $0.2-\mu \mathrm{m}-$ thick partially demineralized zone in Group 9-0-1 (Fig. 2B). In addition, an unusual reticular pattern of nanoleakage that was sporadically located in the mineralized dentin beneath the hybrid layers could frequently be identified in Group 9-0-1 (Fig. 2B), and occasionally in Group 8-1-1 (Fig. 2D).

Group 7-2-1 exhibited minimal nanoleakage within the partially demineralized zone (Fig. 3B) that was predominantly of the spotted type of nanoleakage (Tay et al., 2002) (Fig. 3C). A further increase in the water content of the self-etching primers was not accompanied by an improvement in the quality of dentin hybridization, with moderate (Group 5-4-1; Fig. 4B) to severe nanoleakage (Group 3-6-1; Fig. 4D) observed within the 1.5 - to $2-\mu \mathrm{m}$-thick partially demineralized zones.

\section{DISCUSSION}

It is surprising that very mild etching of the dentin and appreciable tensile bond strength were observed in the anhydrous Group 9-0-1, since water is necessary to ionize the acidic functional groups of self-etching adhesive monomers. The effective ion that causes demineralization of dentin is not the hydrogen ion $\left(\mathrm{H}^{+}\right)$, but the hydronium ion $\left(\mathrm{H}_{3} \mathrm{O}^{+}\right)$, the hydrated hydrogen ion. Since such ions cannot be formed in the absence of water, we speculated that the water responsible for the ionization of the acidic monomers could have been derived from the underlying dentin.

Despite the thinness of the hybrid layers ( $\mathrm{ca} .200 \mathrm{~nm}$ ) in Groups 9-0-1 and 8-1-1, extensive nanoleakage could be identified within the zones of partially demineralized dentin. Conversely, minimal nanoleakage was observed in Group 7-21 , with a thicker hybrid layer $(0.5-1 \mu \mathrm{m})$. Water molecules form hydration clusters around functional groups on collagen peptides and proteoglycans, thereby preventing the interpeptide or peptide-proteoglycan hydrogen bonding that can collapse interfibrillar spaces in the demineralized matrix (Suzuki and Nakai, 1994; Nakaoki et al., 2000; Pashley et al., 2000, 2001). Thus, apart from its role in ionization of the acidic resin monomers, it appears that a minimal water concentration is necessary to keep the demineralized matrix in an expanded stage, even for self-etching primers in which resin infiltration occurs simultaneously with etching of the dentin. This could have accounted for the better resin infiltration and the minimal nanoleakage observed in Group 7-2-1.

The appearance of a reticular pattern of silver-infiltrated interfibrillar spaces beneath the hybrid layers in Group 9-0-1 and occasionally in Group 8-1-1 was unusual, and suggested that continuous etching of the dentin beneath the hybrid layer could have occurred, since the initially non-ionized acidic monomers were converted into their ionic states by water that was derived from the underlying dentin, or during the period of specimen storage in water prior to their laboratory processing. This phenomenon did not occur in the other 3 groups, probably because the acidic monomers were more optimally ionized with the water that was present in these mixed primer solutions, enabling the ionized form of the acidic monomers to exert an immediate etching effect on the underlying dentin. Conversely, delayed ionization of the acidic monomers in Groups 9-0-1 and 8-1-1 could have resulted in non-infiltrated spaces beneath the hybrid layers that were subsequently penetrated by the tracer solution. Water is also useful to solubilize the dissolved calcium and phosphate ions, thereby lowering their ion products below the solubility product constants for various forms of calcium phosphates (McDowell et al., 1977; Shellis et al., 1997). When insufficient water is present, re-precipitation of calcium phosphates within the very fine, partially demineralized interfibrillar spaces of the underlying dentin may have prevented resin infiltration into these regions, resulting in the unusual form of nanoleakage beneath the hybrid layers. The 
hypotheses of delayed ionization of acidic monomers under the condition of an inadequate supply of water, and its possible effect on etching and resin infiltration of dentin, are speculative and require further testing for their validity to be confirmed.

Increasing the water concentration beyond $20 \mathrm{vol} \%$ resulted in further increases in the degree of ionization of the 4-AET monomers, lowering of the $\mathrm{pH}$ of the self-etching primer solutions, and further increasing their depth of demineralization. However, increasing the water concentration also inadvertently diluted the concentrations of the adhesive monomers, thereby lowering their inward rates of diffusion. The water molecules also competed with the adhesive monomers for binding sites on collagen (Vaidyanathan et al., 2003). The excess water may also prevent optimal polymerization of the adhesive monomers. Using $62 \%$ BisGMA $/ 37 \%$ HEMA-based bonding agent, Jacobsen and Söderholm (1995) reported the effect of increasing water concentration on the percent conversion of double bonds, bond strength, and phase changes. As water was added to the bonding agent, the percent conversion fell rapidly from $53.5 \%$ at zero water, to $22.7 \%$ when $20 \%$ water was added. Phase changes may also occur as water is added. Spencer and Wang (2002) examined the amount of water necessary to produce phase changes in $70 \%$ BisGMA/30\% HEMA formulation dissolved in $45 \%$
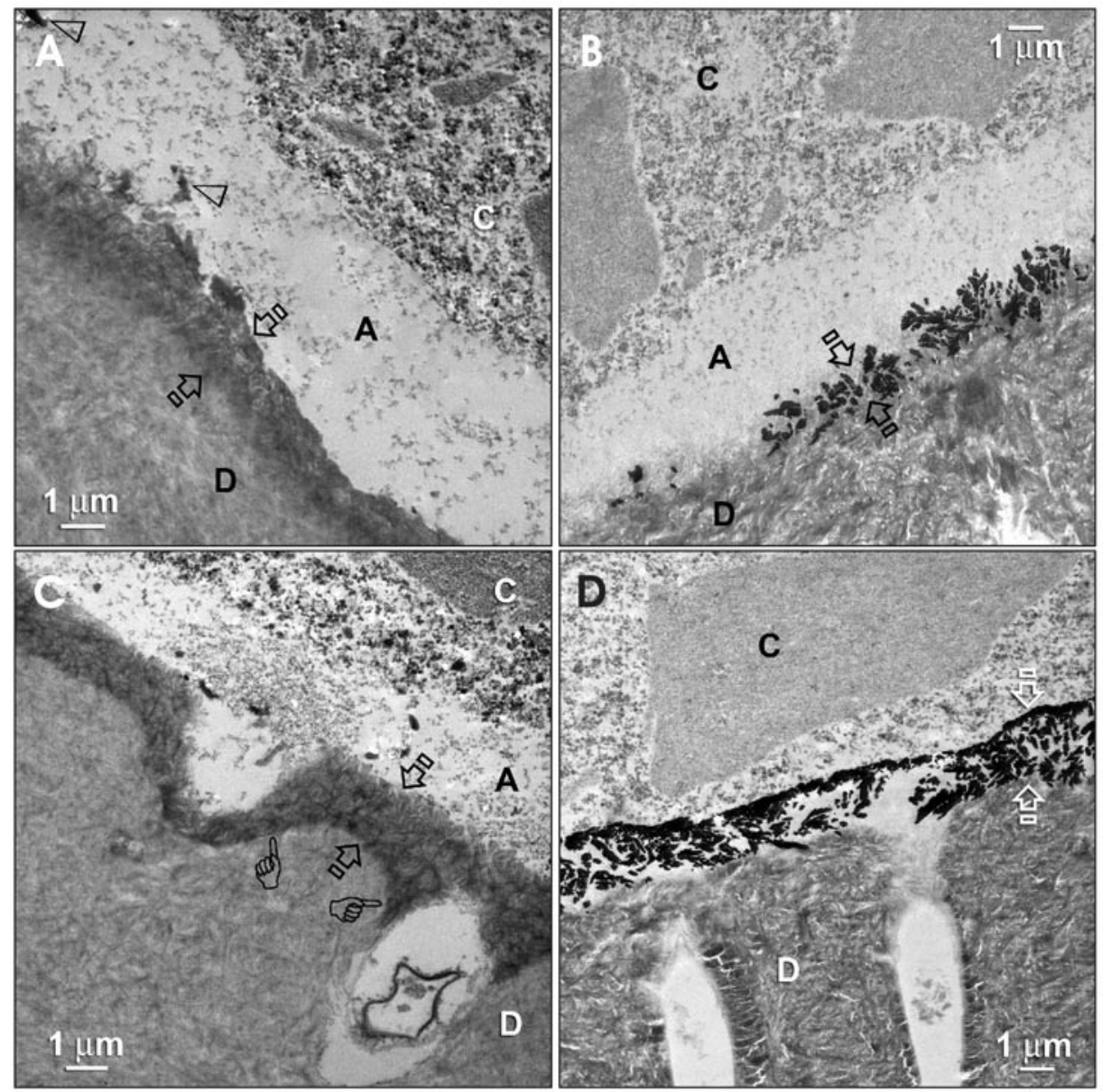

Figure 4. TEM micrographs from (A-B) Group 5-4-1 (40 vol\% water), and (C-D) Group 3-6-1 (60 vol\% water). C, composite; A, filled adhesive; D, dentin. Open arrowhead: F-PRG fillers. (A) Stained, demineralized section from Group 5-4-1. There was an increased aggressiveness of the self-etching primer with increasing water concentration, with the formation of a $1.5-$ to $2-\mu \mathrm{m}$-thick hybrid layer (between open arrows). (B) The corresponding unstained undemineralized section revealed a 1.5 - to $2-\mu \mathrm{m}$-thick partially demineralized zone (between open arrows) in which reticular patterns of nanoleakage could occasionally be seen. There were no silver deposits within the interfibrillar spaces of the underlying dentin. (C) Stained, demineralized TEM from Group 3-6-1, showing a similarly thick hybrid layer (between open arrows), but with further extensions to form peritubular cuffs (pointers) around the dentinal tubules. (D) The corresponding unstained, undemineralized TEM. The low resin concentration and the increased water content resulted in the extensive deposition of silver within the partially demineralized zone (between open arrows). ethanol. This formulation exhibited phase separations at $28 \mathrm{vol} \%$ water.

Without ethanol solvation, the same 70\% BisGMA/30\% HEMA underwent phase separations at around 5 vol\% water. These factors, individually or in combination, could have contributed to the continuous decline in bond strength, and the increasing severity of the nanoleakage in Groups 5-4-1 and 3-6-1, despite the formation of thicker hybrid layers $(c a .1 .5-2 \mu \mathrm{m})$ by these more aggressive self-etching primers.

As the water concentration decreases, the adhesive monomer concentration increases. This tends to increase the viscosity of the formulation, permitting the creation of thicker adhesive concentrations. In a study that examined the microtensile bond strength of an acetone-based adhesive to phosphoric-acid-etched dentin, the highest bond strengths (64 $\mathrm{MPa}$ ) were obtained with $37 \%$ acetone and $63 \%$ comonomers, while the lowest bond strength (38 MPa) was produced by $67 \%$ acetone and 33\% comonomers (Cho and Dickens, 2004).
Clearly, higher monomer concentrations are preferred.

Within the limits of this study, the null hypothesis-that altering the water concentration in two-step self-etching primers has no effect on their aggressiveness and bonding efficacy to dentin-has to be rejected. When self-etching primers are formulated, compromises must be made to provide sufficient water for adequate ionization of the acidic monomers, but without lowering the resin concentration too much to optimize their bonding efficacy to dentin.

\section{ACKNOWLEDGMENTS}

The experimental 4AET/HEMA solution and the resin composite used in this study were generous gifts from Shofu, Inc. This study was supported by RCG CERG grant $10204604 / 07840 / 08004 / 324 / 01$, Faculty of Dentistry, The University of Hong Kong, and by grants DE 014911 and DE 
015306 from the US National Institute of Dental and Craniofacial Research. The authors thank Anna Tay and Edna Pashley for secretarial support.

\section{REFERENCES}

Anseth KS, Scott RA, Peppas NA (1996). Effects of ionization on the reaction behavior and kinetics of acrylic acid polymerizations. Macromolecules 29:8308-8312.

Chersoni S, Suppa P, Grandini S, Goracci C, Monticelli F, Yiu C, et al. (2004). In vivo and in vitro permeability of one-step self-etch adhesives. J Dent Res 83:459-464.

Chigira H, Koike T, Hasegawa T, Itoh K, Wakumoto S, Hayakawa T (1989). Effect of the self etching dentin primers on the bonding efficacy of a dentin adhesive. Dent Mater J 8:86-92.

Chigira H, Yukitani W, Hasegawa T, Manabe A, Itoh K, Hayakawa T, et al. (1994). Self-etching dentin primers containing phenyl-P. $J$ Dent Res 73:1088-1095.

Cho B-H, Dickens SH (2004). Effects of the acetone content of single solution dentin bonding agents on the adhesive layer thickness and the microtensile bond strength. Dent Mater 20:107-115.

Hashimoto M, De Munck J, Ito S, Sano H, Kaga M, Oguchi H, et al. (2004). In vitro effect of nanoleakage expression on resin-dentin bond strengths analyzed by microtensile bond test, SEM/EDX and TEM. Biomaterials 25:5565-5574.

Hayakawa T, Kikutake K, Nemoto K (1998). Influence of self-etching primer treatment on the adhesion of resin composite to polished dentin and enamel. Dent Mater 14:99-105.

Ikemura K, Endo T (1998). Effects of a new 4-acryloxyethyltrimellitic acid in a visible light-cured dental adhesive on adhesion and polymerization reactivity. J Appl Polym Sci 69:1057-1069.

Jacobsen T, Söderholm KJ (1995). Some effects of water on dentin bonding. Dent Mater 11:132-136.

Klotz J, Brostow W, Hess M, Veeman WS (1996). Epoxy and glass composites in water studied with ${ }^{2} \mathrm{H}-\mathrm{NMR}$. Polym Eng Sci 36:1129-1133.

Li H, Burrow MF, Tyas MJ (2003). The effect of concentration and $\mathrm{pH}$ of silver nitrate solution on nanoleakage. J Adhes Dent 5:19-25.

McDowell H, Gregory TM, Brown WE (1977). Solubility of $\mathrm{Ca}_{5}\left(\mathrm{PO}_{4}\right)_{3} \mathrm{OH}$ in the system $\mathrm{Ca}(\mathrm{OH})_{2}-\mathrm{H}_{3} \mathrm{PO}_{4}-\mathrm{H}_{2} \mathrm{O}$ at $5,15,25$, and $37^{\circ}$ C. J Res Natl Bur Stand 81(A):273-281.

Nakabayashi N, Saimi Y (1996). Bonding to intact dentin. J Dent Res 75:1706-1715.

Nakaoki Y, Nikaido T, Pereira PN, Inokoshi S, Tagami J (2000). Dimensional changes of demineralized dentin treated with HEMA primers. Dent Mater 16:441-446.

Nishiyama N, Suzuki K, Yoshida H, Teshima H, Nemoto K (2004a). Hydrolytic stability of methacrylamide in acidic aqueous solution.
Biomaterials 25:965-969.

Nishiyama N, Suzuki K, Takahashi K, Nemoto K (2004b). The pKa effects of the carboxylic acid in N-methacryloyl-omega-amino acid on the demineralization and bond strengths to the teeth. Biomaterials 25:5441-5447.

Pashley DH, Zhang Y, Agee KA, Rouse CJ, Carvalho RM, Russell CM (2000). Permeability of demineralized dentin to HEMA. Dent Mater 16:7-14

Pashley DH, Agee KA, Nakajima M, Tay FR, Carvalho RM, Terada RS, et al. (2001). Solvent-induced dimensional changes in EDTAdemineralized dentin matrix. J Biomed Mater Res 56:273-281.

Pashley EL, Zhang Y, Lockwood PE, Rueggeberg FA, Pashley DH (1998). Effects of HEMA on water evaporation from waterHEMA mixtures. Dent Mater 14:6-10.

Pradelle-Plasse N, Colon P, Wenger F, Picard B (2004). Quantitative evaluation of self-etching primer action on dentin permeability: a correlation between impedance measurements and acidity. Am J Dent 17:131-136.

Shellis RP, Heywood BR, Wahab FK (1997). Formation of brushite, monetite and whitlockite during equilibration of human enamel with acid solutions at 37 degrees C. Caries Res 31:71-77.

Spencer P, Wang Y (2002). Adhesive phase separation at the dentin interface under wet bonding conditions. J Biomed Mater Res 62:447-456.

Suzuki K, Nakai H (1994). Adhesion of restorative resin to tooth substance-treatment of acid-etched dentin by aqueous solution. $J$ Dent Mater 12:34-44.

Tay FR, Pashley DH (2001). Aggressiveness of contemporary selfetching systems. I: Depth of penetration beyond dentin smear layers. Dent Mater 17:296-308.

Tay FR, Moulding KM, Pashley DH (1999). Distribution of nanofillers from a simplified-step adhesive in acid-conditioned dentin. $J$ Adhes Dent 2:103-117.

Tay FR, Pashley DH, Yoshiyama M (2002). Two modes of nanoleakage expression in single-step adhesives. $J$ Dent Res 81:472-476.

Tay FR, Pashley DH, Peters MC (2003). Adhesive permeability affects composite coupling to dentin treated with a self-etch adhesive. Oper Dent 28:610-621.

Vaidyanathan J, Chinnaswamy K, Vaidyanathan TK (2003). Biomimetic recognition and immunochemical assay of ligand binding to collagen. J Adhes Dent 5:7-17.

Van Meerbeek B, De Munck J, Yoshida Y, Inoue S, Vargas M, Vijay P, et al. (2003). Buonocore memorial lecture. Adhesion to enamel and dentin: current status and future challenges. Oper Dent 28:215-235.

Watanabe I, Nakabayashi N, Pashley DH (1994). Bonding to ground dentin by a phenyl-P self-etching primer. J Dent Res 73:12121220. 